\title{
Prediction of changes in landslide rates induced by rainfall
}

\author{
S. Bernardie, N. Desramaut, M. Azib \& G. Grandjean \\ BRGM, Orléans, France (s.bernardie@brgm.fr)
}

\author{
J.-P. Malet \\ Institut de Physique du Globe de Strasbourg, CNRS UMR 7516, EOST, Université de Strasbourg, France
}

\begin{abstract}
This work focuses on the use of a combined statistical-mechanical approach to predict changes in landslide displacement rates from observed changes in rainfall amounts. The forecasting tool associates a statistical impulse response (IR) model to simulate the changes in landslide rates by computing a transfer function between the input signal (e.g. rainfall) and the output signal (e.g. displacements) and a simple 1D mechanical (MA) model (e.g. visco-plastic rheology) to take into account changes in pore water pressures. The models have been applied to forecast the displacement rates at the Super-Sauze landslide (South East France), one of the most active and instrumented clayey landslide in the European Alps. Results indicate that the three models are able to reproduce the displacement pattern in the general kinematic regime with very good accuracy (succession of acceleration and deceleration phases); at the contrary, extreme kinematic regimes such as fluidization of part of the landslide mass are not being reproduced: this statement, quantitatively characterised by the Root Mean Square Error between the model and the observations, constitutes however a robust approach to predict changes in displacement rates from rainfall or groundwater time series, several days before it happens. The variability of the results, depending in particular on the fluidization events and on the location of displacement data is discussed.
\end{abstract}

\section{INTRODUCTION}

Forecasting the displacement pattern of continuously active landslides is a challenge for scientists and risk managers. Changes in displacement rates over time are mostly controlled by hydro-meteorological triggers (e.g. rainstorms, rapid snowmelt) and the consequent increase of pore water pressures, and by geodynamic triggers (e.g. earthquakes, changes in landslide geometry and stress conditions, changes in material rheology). Most of the landslide monitoring systems consist of measurements of rain, pore water pressure and displacements (van Asch et al., 2007).

The most used and reliable approach to forecast the time of failure at single slope scale makes use of displacement (and its derivative, velocity) observations. Other approaches consider the use of rainfall thresholds to analyse the relationship between the triggering precipitation and the movement. The threshold may correspond to a critical value over which the probability of landslide occurrence is higher. Other threshold models are based on dynamic temporal analyses of the rainfall pattern, as the FLaIR model (Sirangelo and Versace, 1992). However, the aforementioned methods do not explicitly consider observed and measured landslide quantities, as they are based on a binary classification (e.g. occurrence or not of a landslide). Analysing the temporal component of a landslide constitutes thus a major improvement in the development of forecasting methods, as suspended and dormant landslides can be reactivated in periods of heavy rainfall, while active landslides may show phases of acceleration and deceleration (Flageollet, 1996; Corominas et al., 2000).

The objective of this work is thus to present the application of a combined statistical-mechanical model to investigate multi-parametric times series of landslide displacements, pore water pressures and rainfall in order to define possible causal inferences among the triggers and the responses of the slope, and to predict the slope kinematics. Three combinations of models are tested. The first model uses a statistical impulse response (IR) function (e.g. TEMPO; Pinault and Schomburgk, 2006), which allows to predict the changes in the landslide rate by computing the transfer function between an input signal (e.g. time series of precipitation) and an output signal (e.g. displacements). The second model uses a simple 1D mechanical (MA) model which combines a simple 1D infiltration model and a visco-plastic rheology to take into account changes in pore water pressures. The third model (IRMA) is a combination of the two previous ones; the IR model allows obtaining the groundwater level from the precipitation time series, and the visco-plastic model is applied using the computed groundwater level time series to simulate the displacements.

The performances of the different combinations of models have been evaluated in previous studies (Bernardie et al., 2011), and the results show that the 3 combinations are complementary according to the different contexts, and should therefore all be considered in parallel. 


\section{DESCRIPTION OF THE FORECASTING MODELS}

\subsection{Impulse Response model - IR}

The impulse response model (IR model) is based on a global approach based on the use of a black box model. It is derived from TEMPO software (Pinault and Schomburgk, 2006), originally dedicated to hydrogeological and hydrogeochemical data analysis. It permits to process data and model temporal series, with computation of transfer functions between input data and output data, based on signal process methods, inversion and optimization technics.

More precisely, this model reproduces an output signal $\mathrm{S}$ using convolution product of an input signal $\mathrm{E}$ by a transfer function $\mathrm{G}$ as described in the equation (1). This function is based on impulse response functions.

$$
S(n . d t)=G * E(t)=\sum_{i=1}^{k} G(i . d t) \cdot E((n-i+1) . d t)
$$

where $\mathrm{n}=$ the discretized interval time, and $\mathrm{k}=$ the order (length) of the impulse response.

The shape of the transfer functions chosen in this study is a convolution of a Gaussian function by an exponential function. Three parameters, T the position of the Gaussian, D, the width of the Gaussian and L, the half time duration of the drainage are necessary to fully define this shape.

Moreover, as the studied landslides are located in a mountain context with the occurrence of snow, the snowmelt is taken into account (Bernardie et al., 2011).

\subsection{Mechanical viscoplastic model - MA}

A 1D infinite viscous model is considered from Herrera et al. (2009). In this approach, the model assumes a pre-existing slip surface, above which the sliding mass moves as a rigid body. It considers a viscoplastic behavior of the landslide. The landslide is assumed to be a translational infinite slide with constant depth $\mathrm{h}$ and constant slope a.

It takes directly into account the daily effective rainfall intensity (rainfall and snowmelt, as defined in paragraph 3) and the dissipation of the excess pore-fluid with using a simple consolidation equation.

The momentum balance equation can be written over the slope direction as:

$\tau-[c+(\sigma n-P w(t)) \cdot \tan \varphi]=m \cdot a(t)+\frac{\eta}{d} v(t)$

where $\tau=$ the destabilizing shear stress; $\sigma_{\mathrm{n}}=$ normal stress; $\phi=$ friction angle; $\mathrm{c}=$ cohesion $; \mathrm{m}=$ mass of the landslide; $\eta=$ viscosity; $d=$ thickness of the shear zone; $p_{w}(t)=$ pore water pressure; $a(t)=$ acceleration and $\mathrm{v}(\mathrm{t})=$ velocity.

With the assumptions of flow parallel to the slope surface, the pore water pressure is defined as:

$p_{w}=z(t) \gamma_{w} \cdot \cos ^{2} \alpha$

where $z(t)=$ position of the groundwater level and $\gamma_{w}=$ specific weight of water. Changes in groundwater level have been taken directly proportional to the effective rainfall intensity:

$\mathrm{dz}=\mathrm{I}_{\text {rainfall }} / 1000 / \mathrm{n}$

where $\mathrm{I}_{\text {rainfall }}=$ effective rainfall in $\mathrm{mm} / \mathrm{m}^{2} /$ day and $\mathrm{n}=$ porosity.

The dissipation of the excess pore water pressure in the saturated layer is governed by the Terzaghi's one dimensional consolidation theory, as described in the following relationship:

$e p_{w}=e p_{w 0} \cdot \mathrm{e}^{-t / T v}$

where $\mathrm{ep}_{\mathrm{w} 0}=$ initial excess pore water pressure and $\mathrm{T}_{\mathrm{v}}=$ time factor controlling the dissipation time of the excess pore pressure defined as:

$T v=\frac{4 h^{2}}{\pi^{2} C v}$

where $\mathrm{C}_{\mathrm{v}}=$ consolidation coefficient.

Prediction of the displacement is obtained by solving the equation 3, with using optimization functions, permitting to optimize some geometry parameters (h and d), and some material properties $\left(\rho, \phi, \eta, n\right.$ and $T_{v}$ parameters). 


\subsection{Coupled statistical-mechanical (IRMA) model}

This model combines the IR and MA models. The IR model is used to simulate groundwater level from the rain and temperature observed time series; then the mechanical part of the MA model is used to compute the displacement rate of the landslide directly from the computed groundwater levels transformed in pore water pressures.

\section{DESCRIPTION OF THE SUPER-SAUZE LANDSLIDE}

The studied landslide is located in the French south Alps in the Barcelonnette Basin, on the left bank of the Ubaye River. The Super-Sauze landslide is a continuously active mudslide, within the Callovian-Oxfordian black marls. The mudslide extends over a horizontal distance of $850 \mathrm{~m}$, and occurs between an elevation of $1740 \mathrm{~m}$ and $2105 \mathrm{~m}$ with an average slope of $25^{\circ}$. The total volume is estimated at $750000 \mathrm{~m}^{3}$.

From a hydrological and geotechnical viewpoint, the mudslide is structured in two vertical units: the first unit (5 to $10 \mathrm{~m}$ thick) is a moderately stiff and semi-permeable material, while the second unit (with a maximum thickness of $10 \mathrm{~m}$ ) is a stiff and impervious material (Malet and Maquaire, 2003). Both materials involve low plasticity, intensely fissured reworked black marls with a sandy-silt matrix.

Deformation occurs as a consequence of a rise of the perennial groundwater table, resulting in the development of positive pore pressures in the moving material. Groundwater fluctuations are controlled by water infiltration both in the soil matrix and in large kinematical cracks and fractures as well as recharge from the torrents bordering the landslide (Malet et al., 2005; de Montety et al., 2007).

The contact between the active mudslide and the stable hillslopes comprises a shearing zone of a few meters width characterized by tension cracks.

\section{CALIBRA TION OF THE MODEL}

The objective of the model application is to predict daily displacement from the precipitation time series. Therefore, the calibration procedure has been performed on a daily basis by optimizing model performance over several sizes of time windows. The used optimization algorithm is the SQP method (Sequential Quadratic Programming) (Boggs and Tolle, 1995) which is adapted to the optimization of non-linear dynamic systems. Several parameters have to be optimized with this procedure:

- For the IR model, for each type of input of the model (i.e. rainfall, snow melt and source) the parameters $T, D$ and $L$ are optimized. The respective contributions of these inputs components to the response of the mass movement, as well as the coefficient $c$, are also optimized.

- For the ME model, the choice of the parameters to be optimized depends on the knowledge of the parameters for the specific site. For instance in the case of Super-Sauze landslide, six parameters are optimized $\phi, \rho, \eta, n, T_{v}$ and $h$ and the other parameters are fixed.

- For the IR-ME model, the same parameters than for the IR model are optimized, including also the $z_{\max }$ and the adequate parameters of the mechanical part of the ME model), so in this case $\phi, \rho$ and $\eta$.

The performance of the model is evaluated with the Nash and RMSE (Root Mean Square Error) statistical criteria.

\section{APPLICATION OF THE METHODOLOGY: PREDICTION OF FLUIDIFICATION EVENTS}

In order to test the ability of the methodology to be used in an operative alert system delivering daily warnings in nearly real time, a prediction procedure has been developed and tested. The method has been applied as if the new data were received each morning and treated in real time, on a daily basis. Hence, for each day, the "new" received data are added to the historical time series. The models are calibrated as presented in the previous paragraph, over time windows with different widths. The optimal calibration is then used to predict the displacement for the three following days, based on the meteorological data of these three next days, assumed to be meteorological predictions. The procedure is then repeated for the next day, with a complete new calibration, and so on. 

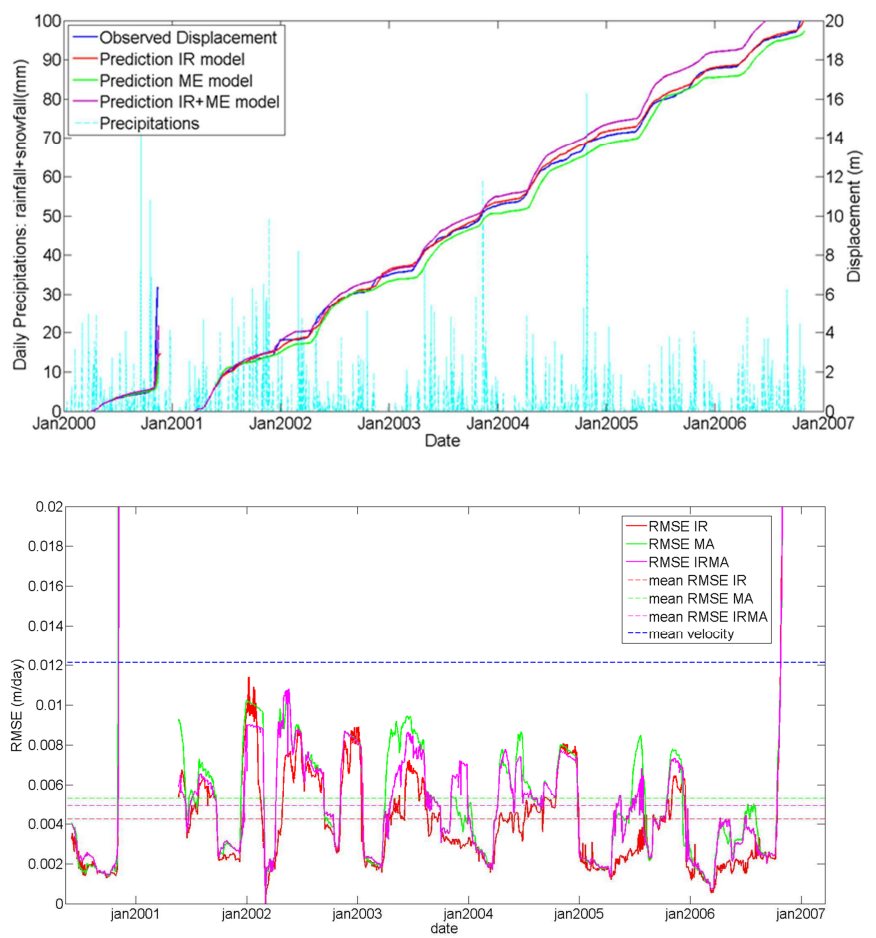

Figure 1. Predicted and observed cumulated displacements, and corresponding RMSE

The daily predicted displacements are compared with the observed displacements (Fig. 1 and Fig.2). With this approach, the IR model provides the best predicted displacements; the IRMA model overestimates the displacement for the second part of the curve, and the MA model slightly underestimates the displacements. These results suggest that the 3 models are adapted to predict the movements for a period of 3 following days in a normal regime.

a)

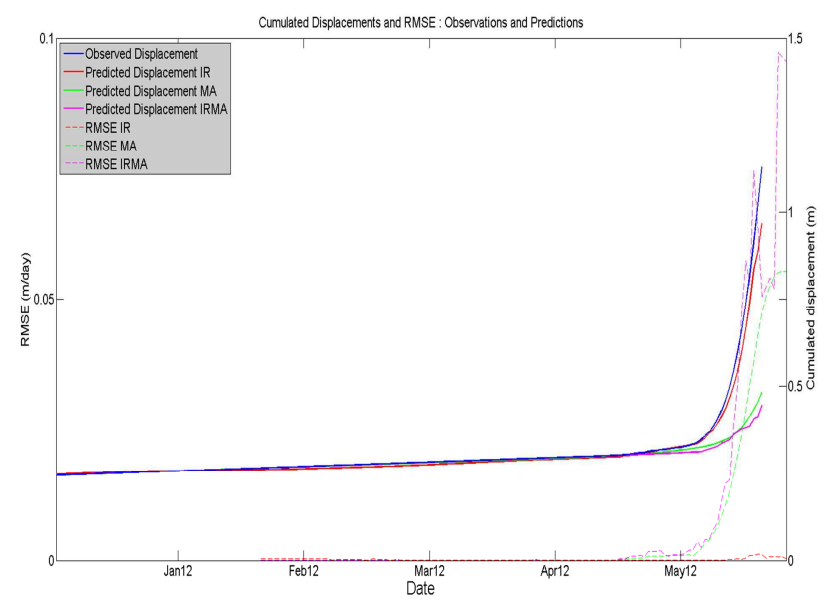

b)

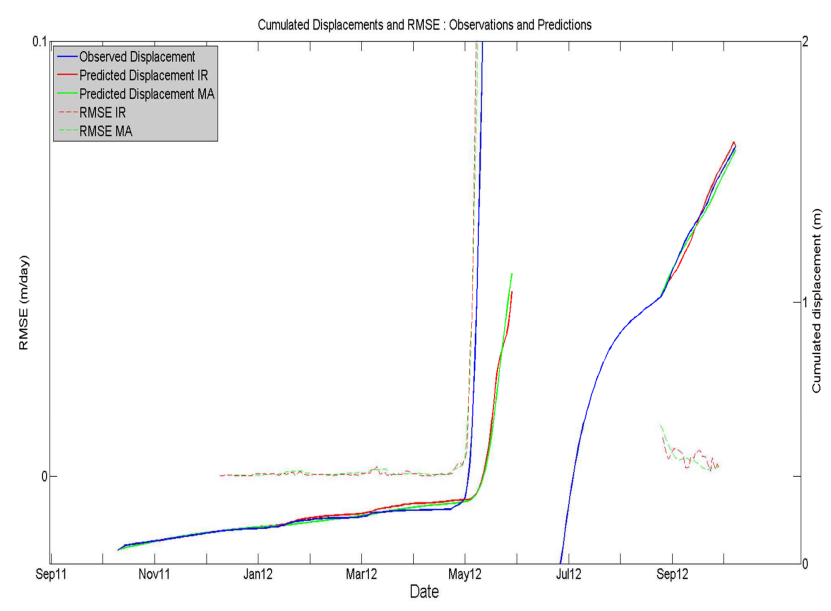

Figure 2. Predicted and observed cumulated displacements, and corresponding RMSE, for 2 instrumented sites on the landslides (a, SAZ1, b, SAZ2)

During the period preceding the occurrence of a fluidization event the model is not able to reproduce the displacement with a good accuracy anymore. Indeed, the RMSE criterion computed on the 3 predicted days, largely increases, as seen on Figure 3, possibly indicating an important change in the behaviour and the kinematic regime of the landslide. Moreover, the large increase of this criterion appears only before the occurrence of a flow. This interesting result suggests that the RMSE variation could be a good indicator of the occurrence of a fluidization event several days before the occurrence of the event itself 


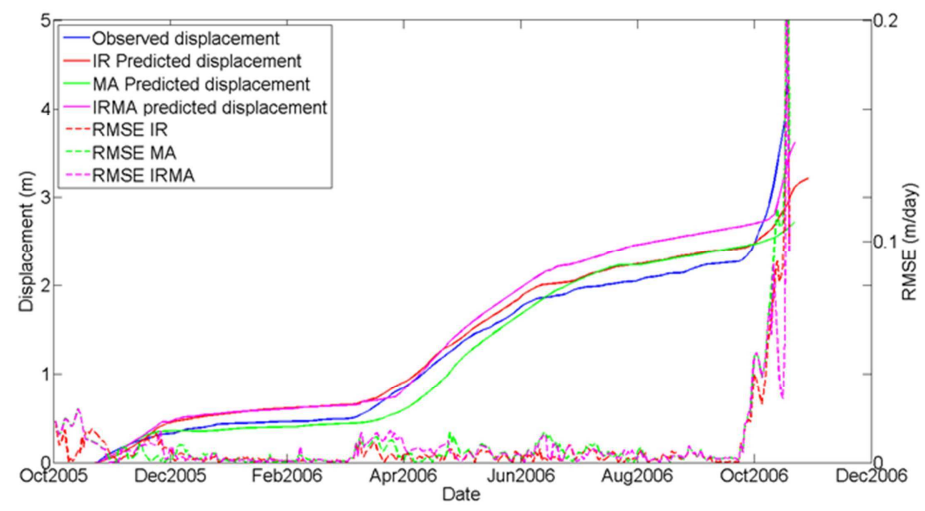

Figure 3. Predicted and observed cumulated displacements

It is then essential to find rigorous thresholds for warning the occurrence of a catastrophic fluidization event. The two first proposed thresholds are based on the normal law distribution of the RMSE values, with the use of a threshold equal to the mean of the RMSE plus three standard deviation values of the RMSE ( $\left.t_{1 a}\right)$ and the second one $\left(\mathrm{t}_{1 \mathrm{~b}}\right)$ equal to mean of the RMSE plus one standard deviation values of the RMSE:

$t 1 a=\operatorname{mean}(x)+3 \sigma_{x}$

$t 1 b=\operatorname{mean}(x)+\sigma_{x}$

A third threshold is defined, based on the distribution of the sorted RMSE. The threshold is then chosen at the limit of curve between the low and the high values, at the inflexion point of the distribution.

These thresholds are proved to be efficient to predict the occurrence of the fluidization for the study case. . However, the distribution threshold based on the inflexion point does not seem to be robust enough to be used in an early warning system. It is highly dependent on the length of the observed dataset .Therefore this threshold is not considered further.

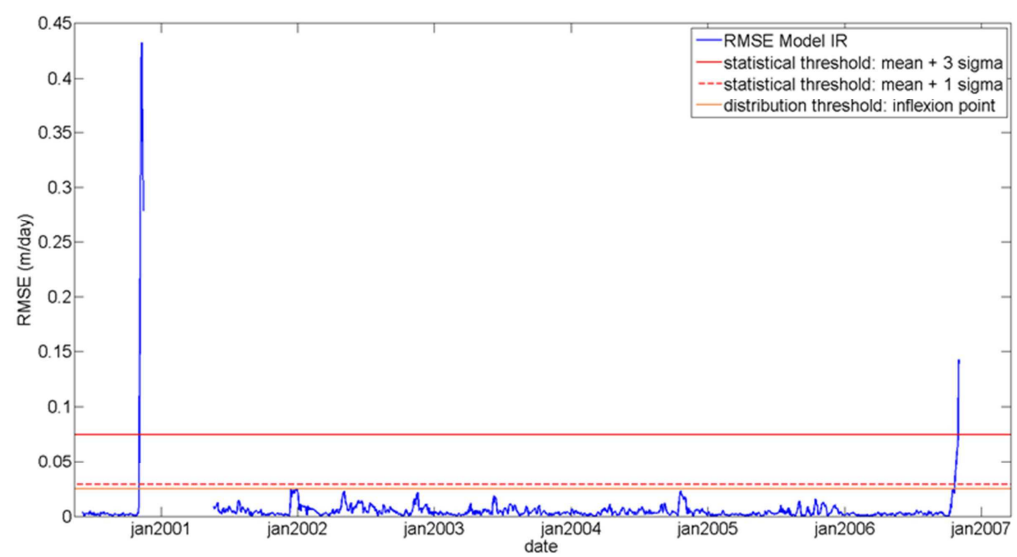

Figure 4:Predicted RMSE and thresholds for the IR model for the 2001-2006 period

The prediction capabilities of the different models are proved to be fairly good in term of time of delay according to the selected threshold (Table1), except in few occasions, mostly on the slower part of the landslide (SAZ1), where the fluidification event was less important in 2012. Otherwise, the delay is similar to the criteria derived from velocities, but our method has the advantage to be also based on other measures, making the early warning system potentially more robust.

Table 1. Delay of alert before the occurrence of the flow (in day)

\begin{tabular}{|c|c|c|c|c|c|c|c|c|}
\hline \multirow[t]{2}{*}{ Delay in Day } & \multicolumn{2}{|c|}{2000 flow } & \multicolumn{2}{|c|}{2006 flow } & \multicolumn{2}{|c|}{2012 flow (SAZ1) } & \multicolumn{2}{|c|}{2012 flow (SAZ2) } \\
\hline & tla & $\mathrm{t} 1 \mathrm{~b}$ & t1a & $\mathrm{t} 1 \mathrm{~b}$ & t1a & $\mathrm{t} 1 \mathrm{~b}$ & $\mathrm{t} 1 \mathrm{a}$ & $\mathrm{t} 1 \mathrm{~b}$ \\
\hline Observed velocity & 11 & 11 & 7 & 19 & 4 & 8 & 9 & 14 \\
\hline Model IR & 11 & 11 & 3 & 11 & - & 2 & 6 & 12 \\
\hline Model MA & 11 & 11 & 2 & 11 & 2 & 8 & 5 & 11 \\
\hline Model IRMA & 8 & 9 & 10 & 19 & - & 5 & 4 & 9 \\
\hline
\end{tabular}


The capability to predict the complex displacement pattern (acceleration, deceleration) of landslide is an important issue for early-warning. Most of the current alarm systems are based on simple criteria, such as cumulated precipitation thresholds, which can provide false alarms and make them therefore unreliable for people.

A methodology has therefore been tested to combine meteorological observations with statistical and mechanical models to simulate the kinematics of landslides in their normal regime. The three proposed models demonstrate their capability to reproduce the landslide movements in ordinary situations, but not during fluidification events. Hence, these changes in modelling capacities of the models appear to be some good criteria to predict the acceleration of the landslides. Furthermore, the use of models based on different approaches, either statistical or mechanical, ensures their complementarity.

One limitation of the model is that due to conditions in mountainous context and the dynamic of the object of study, most of the data might require some preprocessing. Snow depth measures are often lacking and snow accumulation and additional water input due to snow melting should therefore often be assessed based on empirical relationships (e.g. solution of degree-day adopted in our tool). Meteorological observations and predictions could also correspond to a station which is not located close to the monitored landslide.

Another question raised by the approach is the selection of the most pertinent thresholds. The use of statistical criteria, even if objective and robust, could be dependent on the length of the dataset. The use of other detection technics, such as the studied and so-called inflexion point, might be somewhat subjective and highly dependent on the historical data.

The proposed tool has proven to be valuable for the case study, with the aforementioned assumptions, and for the specific studied period, during which three fluidification events happened. In order to extend the methodology and to make it a potential generic warning system, it would however be necessary to test it on other sites to assess, for example, the potential influence of other geomorphological contexts or climatic patterns (such as the absence of snow) on the validity of the methodology.

This type of approach, quite innovative, would help to gather sufficient information from different sources of information (monitoring at the slope, model simulations) in order to find out if and when a slope is approaching its collapse and to reduce the uncertainties (e.g. heuristic experience of the expert) in the assessment.

\section{REFERENCES}

Bernardie S., Desramaut N., Russo G., Zurcher J., Grandjean G. 2011. Prediction of changes in landslide rate induced by rainfalls: from the use of a black box model to a 1D mechanical mode. Proc Journées Aléa Gravitaire, 7-8 September. 2011, Strasbourg, France

Corominas, J., Moya, J., Ledesma, A., Lloret, A. and Gili, J.A. 2005. Prediction of ground displacements and velocities from groundwater level changes at the Vallcebre landslide (Eastern Pyrenees, Spain). Landslides, 2: 83-96.

De Montety V., Marc V., Emblanch C., Malet J.-P., Bertrand C., Maquaire O. and Bogaard T.A. 2007. Identifying origin of groundwater and flow processes in complex landslides affecting black marls: insights from an hydrochemistry survey. - Earth Surface Processing and Landforms 32 (1): 32-48.

Flageollet, J.-C. 1996. The time dimension in the study of mass movements. Geomorphology 15: 185-190.

Herrera, G., Fernandez-Merodo J.A., Mulas J., Pastor M. Luzi G. and Monserrat O. 2009. A landslide forecasting model using ground based SAR data: The Portalet case study, Engineering Geology, 105: 220-230.

Kustas W.P., Rango A. and Uijlenhoet R. 1994. A simple energy budget algorithm for the snowmelt runoff model. Water Ressource Research 30(5): 1515-1527.

Malet J.-P. \& Maquaire O. 2003. Black marl earthflows mobility and long-term seasonal dynamic in southeastern France. In: Proc. $1^{\text {st }}$ International Conference on Fast Slope Movements, 14-16 May, Naples, Italy. 333-340. Patron Editore, Bologna.

Malet J.-P., Van Asch T.W.J., Van Beek L.P.H. and Maquaire O. 2005. Forecasting the behavior of complex landslides with a 2-5D spatially distributed hydrological model. Natural. Hazard. and Earth System. Science 5: 1-15.

Pinault, J.-L. \& Schomburgk S. 2006. Inverse modeling for characterizing surface water/groundwater exchanges, Water Resour. Res., 42, W08414,doi:10.1029/2005WR004587.

Sirangelo, B. \& Versace, P. 1992. Modelli stocastici di precipitazione e soglie pluviometriche di innesco dei movimenti franosi. Proc. XXIII Convegno Nazionale di Idraulica e Costruzioni Idrauliche, 31 August - 4 September, Florence, Italy: D361-D373.

van Asch, T.W.J., Malet, J.-P., van Beek, L.P.H. and Amitrano, D. 2007. Techniques, advances, problems and issues in the modelling of landslide hazard. Bulletin de la Société Géologique de France, 178(2): 6-35. 